\title{
ROAD DETECTION FROM REMOTE SENSING IMAGES USING IMPERVIOUS SURFACE CHARACTERISTICS: REVIEW AND IMPLICATION
}

\author{
Pankaj Pratap Singh ${ }^{1}$ and R. D. Garg ${ }^{2}$ \\ ${ }^{1}$ Research Scholar, ${ }^{2}$ Associate Professor \\ Geomatics Engineering Group, Department of Civil Engineering \\ Indian Institute of Technology Roorkee, Roorkee - 247667 INDIA \\ E-mail- pankajps.iitr@gmail.com ${ }^{1}$, garg_fce@iitr.ac.in ${ }^{2}$
}

KEY WORDS: Classification Techniques, HRSI, Impervious Surfaces, Information Extraction, Road Detection

\begin{abstract}
:
The extraction of road network is an emerging area in information extraction from high-resolution satellite images (HRSI). It is also an interesting field that incorporates various tactics to achieve road network. The process of road detection from remote sensing images is quite complex, due to the presence of various noises. These noises could be the vehicles, crossing lines and toll bridges. Few small and large false road segments interrupt the extraction of road segments that happens due to the similar spectral behavior in heterogeneous objects. To achieve a better level of accuracy, numerous factors play their important role, such as spectral data of satellite sensor and the information related to land surface area. Therefore the interpretation varies on processing of images with different heuristic parameters. These parameters have tuned according to the road characteristics of the terrain in satellite images. There are several approaches proposed and implemented to extract the roads from HRSI comprising a single or hybrid method. This kind of hybrid approach has also improved the accuracy of road extraction in comparison to a single approach. Some characteristics related to impervious and non-impervious surfaces are used as salient features that help to improve the extraction of road area only in the correct manner. These characteristics also used to utilize the spatial, spectral and texture features to increase the accuracy of classified results. Therefore, aforesaid characteristics have been utilized in combination of road spectral properties to extract road network only with improved accuracy. This evaluated road network is quite accurate with the help of these defined methodologies.
\end{abstract}

\section{INTRODUCTION}

Over the years, the road network has appeared to facilitate the needs of automatic map generation for route planning and control of the transportation system especially in remote and unreachable areas. These all needs owe towards the automatic and accurate road detection method.

The classification of High resolution satellite images (HRSI) is quite useful to extract the relevant information viz. Roads. The availability of trees in satellite images is found adjacent to roads, which majorly affected the road classes due to its shadow effects. It is one of the major causes that reduced the accuracy of road extraction in HRSI. While keeping these challenges in the mind, various hybrid road detection approaches on satellite images was carried out. However, on the basis of qualitative analysis, it has been observed that the thresholding-based method has limitations of occluding the connected non-road area as well as in the spectrally homogeneity region on HRSI. In the manner of such kind of work, a four modules based methods have utilized in such a way to extract road network; preprocessing; fusion of information; edge based derived information (Mena and Malpica, 2005).

A semi-automatic approach has used a reference template that comprises roads related salient information, to extract the urban road networks. Thereafter, Euclidean distance transformation (EDT) is applied to remove the small noises followed by the aforesaid approach (Lin et al., 2011). Morphological profiles are also presented to extract linear geometrical information with the help of path openings and closings. It helps to classify pixel either in road or non-road class (Valero et. al., 2010). In addition, an integrated solution is used, which comprises Gabor filtering, tensor voting and optimized segmentation techniques into a unified framework to extract the road segments and transforming them to their polygonal representations (poullis and You., 2010). An available road verification map is required for updating the existing road maps, in the respective way of changes occurred in the urban areas. An approach is based on the ant agents, which takes an appropriate decision to distinguish the of pixel as road or non-road (Zarrinpanjeh et. al., 2013). The Occurrence of challenges in impervious surfaces for road detection in remote sensing images is shown in figure 1 . In the road area of the images with the attached impervious surfaces that could be the non-road area. Therefore, a single method is not sufficient to remove this non-road area. This task has become more difficult in case of the spectral similarity in between these impervious surfaces. It helps to analyze the satellite images to find out the key challenges in the road detection approaches.

\section{RELATED REVIEW WORK ON ROAD DETECTION}

Many researchers have proposed different methods to extract roads object such as multi-scale grouping, model-based approach, mathematical morphology, fuzzy-based, fusion-based and dynamic programming (Mohammadzadeh et al., 2009; Mohammadzadeh et al., 2007). A fuzzy-based mean calculation method is proposed (Mohammadzadeh et al., 2009), which is optimized by a Particle swarm optimization (PSO). It also evaluates the best mean values for road detection in particular spectral band, which also improves the fuzzy cost function.

\footnotetext{
${ }^{1}$ Corresponding author
} 
Finally, centerline of road extracted with the help of mathematical morphology. A self-learning fuzzy and Genetic algorithm (GA)-based approach is proposed to overcome the global and continuous searching problem in the calculation of parameters for the fuzzy membership function (Mohammadzadeh et al., 2007). The best mean values is calculated for segmentation of images. Therefore, centerline of roads helped to remove small non-road segments of the segmented image (Mohammadzadeh et al., 2008).

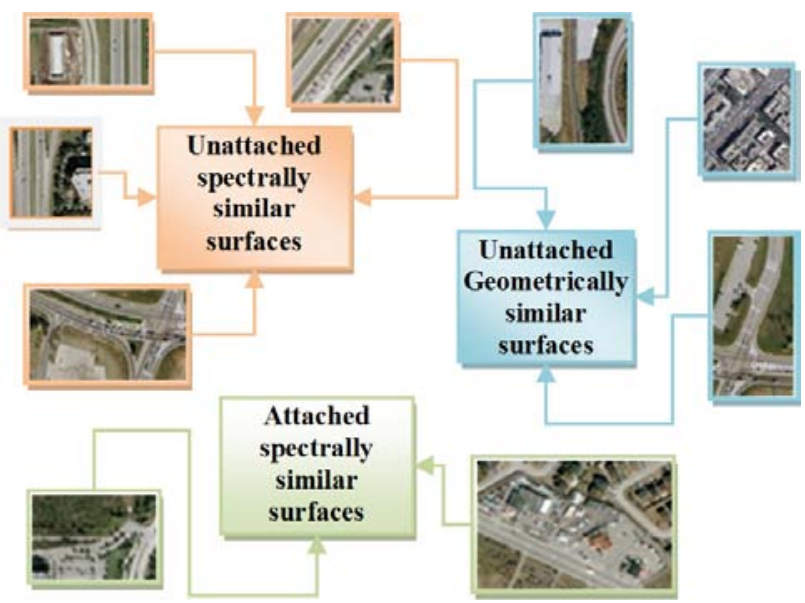

Figure 1. Occurrence of challenges in impervious surfaces for road detection in remote sensing images

To update the Geographic Information System (GIS) database, (Zelang et al. 2013) a road extraction approach is proposed, which is based on shape features and multivariate adaptive regression splines (MARS). The measurement of optimally oriented flux (OOF) helps to eliminate the undesired spurs for the selection of end points from a classified image and further these end points are connected accurately to formulate the road network using a geodesic method (Zelang and Wenzhong 2014).

The spectral reflectance of asphalt surface helps to distinguish road surface from other impervious surfaces (Singh and Garg, 2013). The controlling parameters have utilized in the fuzziness of the FCM approach, which help to estimate the segmented road results and thereafter Stentiford thinning algorithm (STA) is used to estimate the road network from classified results. Such improvements facilitate FCM method manipulation and lead to segmentation that is more robust (Singh and Garg, 2014a). The process of road extraction may be achieved in a single or multiple operations such as image segmentation (classification techniques), linear segments with constant width (Hough transform and edge detector), snakes (contour based object outlines), removing small blobs and merging relevant road segments (morphological operations), similarity with road templates, etc. Many methodologies have been proposed and implemented to extract the roads from HRSI and also tried to reduce the time complexity.

\section{OVERVIEW OF ROAD DETECTION FROM HIGH RESOLUTION SATELLITE IMAGES}

The road network is useful information in the satellite images, which helps in the applications related to urban planning and traffic flow analysis. The different categories of road network in such kind of applications are utilized to renovate the roads and also recognize the variability in the roads. These image classification-based approaches help to detect the roads in the images, which is not adequate for the remote user to conclude the roads information.

Table 1 shows the road characteristics in HRSI of different areas. It consists of different kind of satellite sensors that are utilized to cover different types of classes/objects. Basically the satellite sensors are utilized only in the spectral resolution of images that is not sufficient enough to extract the roads accurately in comparison to other available classes in HRSI. Some other factors are also highly impactful in the road classification from the remote sensing images (Table 2). These highly Impacting factors are also taken consideration in the road characteristics of the satellite images in different areas for the better road results.

\begin{tabular}{|c|c|c|c|}
\hline & \multicolumn{3}{|c|}{ Road characteristics } \\
\hline $\begin{array}{c}\text { Different } \\
\text { areas }\end{array}$ & Geometrical & Spectral & $\begin{array}{c}\text { Surface } \\
\text { material }\end{array}$ \\
\hline $\begin{array}{l}\text { Developed } \\
\text { urban }\end{array}$ & $\begin{array}{l}\text { Linear, } \\
\text { curvilinear }\end{array}$ & $\begin{array}{c}\text { Similarity with } \\
\text { concrete surfaces }\end{array}$ & $\begin{array}{c}\text { Asphalt, } \\
\text { concrete, } \\
\text { Warm mix }\end{array}$ \\
\hline $\begin{array}{l}\text { Developed } \\
\text { suburban }\end{array}$ & $\begin{array}{c}\text { Linear, } \\
\text { curvilinear, } \\
\text { continuous } \\
\text { parallel structure } \\
\text { with connected } \\
\text { small roads }\end{array}$ & \multirow{2}{*}{$\begin{array}{l}\text { Changes in } \\
\text { spectral behavior } \\
\text { of the Earth's } \\
\text { surface } \\
\text { objects due } \\
\text { to aging factor }\end{array}$} & $\begin{array}{c}\text { Asphalt, } \\
\text { cold mix } \\
\text { (rural roads) }\end{array}$ \\
\hline $\begin{array}{l}\text { Emerging } \\
\text { urban }\end{array}$ & $\begin{array}{l}\text { Linear, } \\
\text { curvilinear }\end{array}$ & & \begin{tabular}{|c} 
Hot mix \\
(highway, \\
free floating \\
screed)
\end{tabular} \\
\hline $\begin{array}{l}\text { Emerging } \\
\text { suburban }\end{array}$ & $\begin{array}{c}\text { Linear, } \\
\text { curvilinear, } \\
\text { continuous } \\
\text { parallel structure } \\
\text { with elevation } \\
\text { factor }\end{array}$ & $\begin{array}{l}\text { Changes in } \\
\text { Atmospheric } \\
\text { condition and } \\
\text { sun position } \\
\text { during day-time } \\
\text { over the year }\end{array}$ & $\begin{array}{c}\text { Hot mix } \\
\text { (highway, } \\
\text { free floating } \\
\text { screed) }\end{array}$ \\
\hline
\end{tabular}

Table 1. Road characteristics of the satellite images in different areas

\begin{tabular}{|c|c|c|}
\hline & \multicolumn{2}{|c|}{$\begin{array}{l}\text { Highly impacting factor in the road } \\
\text { characteristics }\end{array}$} \\
\hline $\begin{array}{l}\text { Different } \\
\text { Areas }\end{array}$ & $\begin{array}{c}\text { Surrounding } \\
\text { area }\end{array}$ & $\begin{array}{c}\text { Temporal affects } \\
\text { (Road aging and deterioration) }\end{array}$ \\
\hline $\begin{array}{l}\text { Developed } \\
\text { urban }\end{array}$ & $\begin{array}{c}\text { Buildings and } \\
\text { Trees }\end{array}$ & Cracks and raveling \\
\hline $\begin{array}{l}\text { Developed } \\
\text { suburban }\end{array}$ & $\begin{array}{l}\text { Parking area } \\
\text { and Trees }\end{array}$ & $\begin{array}{l}\text { Quality of pavement } \\
\text { material, traffic flow }\end{array}$ \\
\hline $\begin{array}{l}\text { Emerging } \\
\text { urban }\end{array}$ & $\begin{array}{l}\text { Trees and } \\
\text { vegetation }\end{array}$ & \multirow{2}{*}{$\begin{array}{l}\text { Quality of pavement } \\
\text { material, traffic flow, } \\
\text { and natural calamities }\end{array}$} \\
\hline $\begin{array}{l}\text { Emerging } \\
\text { suburban }\end{array}$ & $\begin{array}{l}\text { Vegetation } \\
\text { and forest }\end{array}$ & \\
\hline
\end{tabular}

Table 2. Highly impacting factor in the road characteristics of different urban areas

In the reference of these aforesaid issues, various kinds of information in satellite Images have played a major role in road extraction (Figure 2). It shows the different stages to achieve the road detection in HRSI, which also comprises various kinds 
of information such as contextual, Geometrical, Spatial, Spectral and surroundings. It also required a large number of training samples to justify the results with the combination of appropriate information. Basically, the methods for road classification are approached to sense the changes around their vicinity and extract the road results.

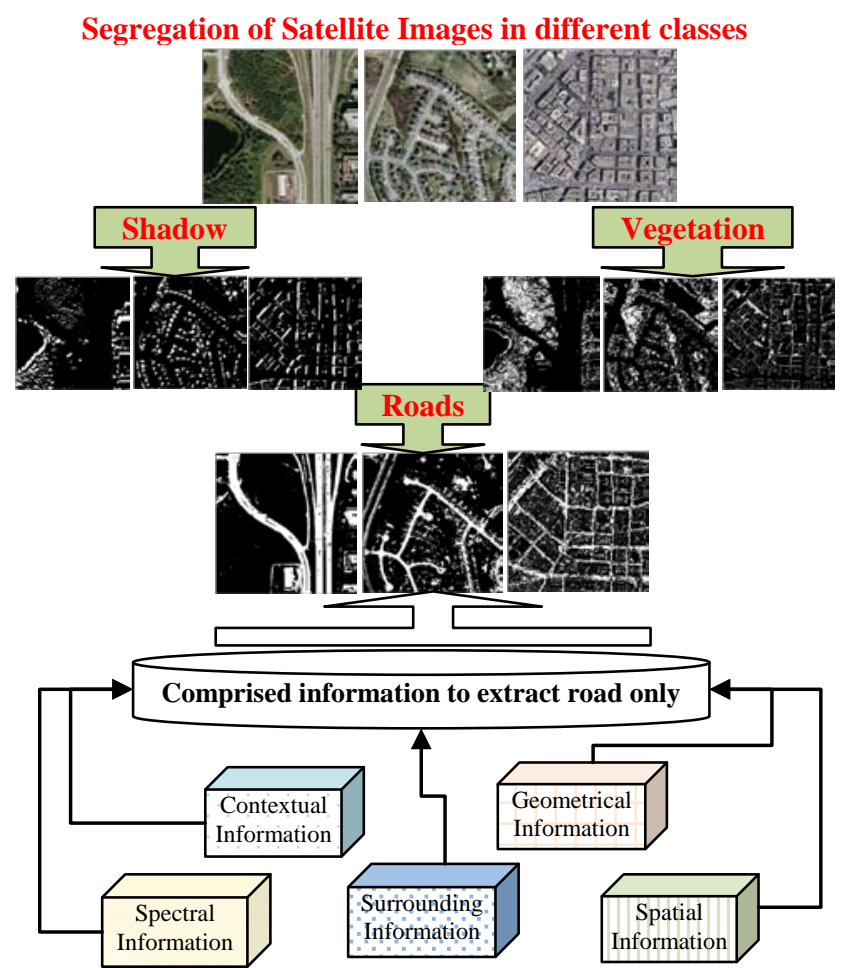

Figure 2. Role of various kinds of information in satellite Images for road extraction

The segmentation methods are used to segregate the existing classes in HRSI and further these segmented images are utilized according to the user's interest or urban planning applications. Based on the demanding of linear feature extraction, image classification techniques have approached to distinct the road and non-road areas. Non-road areas include both impervious (parking lot and roof's) and non-impervious (trees, vegetation and buildings) surfaces, even though and shadow effect also affected a high impact incorrectly classify road network.

The reason is quite obvious for low implosion, due to the little variation in spectral behavior of parking area, roads, and roof. The incorporation of other information is also an important task.

\section{HYBRID APPROACHES FOR ROAD DETECTION}

In recent times, the extraction of road centerline from HRSI has been achieved with the help of different integrated approaches such as different neighboring pixels to segregate the road and non-road areas. For further improvement in road class, shape based features were also utilized (Shi et al. 2014). To resolve the problem of curvilinear and close features, the integrated approach that comprises of tensor voting, principal curves, and the geodesic method is used to extract the road centerline (Zelang et al., 2014a). A geodesic method was also utilized differently in multi-stages to extract the road centerline (Zelang et al. 2014b).
A two-step method for road centerline extraction from HRSI was proposed by Wenzhong et al. (2014). They segmented the imagery using spectral-spatial classification and then further shape features were used to improve the accuracy of road class. All these approaches have been tested for the extraction of road centerline in the urban area from HRSI.

A hybrid approach is implemented to achieve the road extraction from HRSI by using adaptive global thresholding and morphological operations (Singh and Garg, 2012). In this Image segmentation based approach, initially performed global thresholding to segment the image to fix the boundaries and thereafter morphological operations is utilized to renovate the road network. Two stages based framework is proposed that utilizes Intermediate Stages (IS) incorporating the prominent features of roads to renovate the classified road network in a better way (Singh and Garg, 2014b).

\begin{tabular}{|c|c|c|c|c|c|}
\hline Description & $\begin{array}{c}\text { Mena and } \\
\text { Malpica, } \\
2005\end{array}$ & $\begin{array}{l}\text { Valero et } \\
\text { al., } 2010\end{array}$ & $\begin{array}{l}\text { Lin et al., } \\
2011\end{array}$ & $\begin{array}{c}\text { Zarrinpanjeh } \\
\text { et al., } 2013\end{array}$ & $\begin{array}{c}\text { Singh } \\
\text { and Garg, } \\
\text { 2014b }\end{array}$ \\
\hline $\begin{array}{l}\text { Multistage } \\
\text { framework }\end{array}$ & $\begin{array}{c}\text { Hierarchical } \\
\text { level }\end{array}$ & $\begin{array}{c}\text { Hierarchical } \\
\text { level }\end{array}$ & Sequential & Distributed & Sequential \\
\hline $\begin{array}{c}\text { Hybrid } \\
\text { approach }\end{array}$ & Yes & No & Yes & No & Yes \\
\hline $\begin{array}{c}\text { Pre- } \\
\text { processing }\end{array}$ & $\begin{array}{l}\text { Single } \\
\text { level }\end{array}$ & $\begin{array}{c}\text { To remove } \\
\text { connected } \\
\text { non-road } \\
\text { pixels } \\
\text { (Future } \\
\text { work) } \\
\end{array}$ & $\begin{array}{c}\text { Image } \\
\text { smooth-ness }\end{array}$ & $\begin{array}{c}\text { Omission of } \\
\text { redundant } \\
\text { nodes }\end{array}$ & Stage-I \\
\hline $\begin{array}{c}\text { Post- } \\
\text { processing }\end{array}$ & No & \begin{tabular}{|c|} 
To fully \\
connect the \\
road graph \\
(Future \\
work) \\
\end{tabular} & $\begin{array}{c}\text { Yes (road } \\
\text { boundary } \\
\text { and the } \\
\text { junctions) }\end{array}$ & No & No \\
\hline $\begin{array}{c}\text { Completely } \\
\text { extracted }\end{array}$ & Yes & No & $\begin{array}{c}\text { Yes } \\
\text { (Urban } \\
\text { areas only) }\end{array}$ & Yes & Yes \\
\hline $\begin{array}{l}\text { Correctly } \\
\text { extracted }\end{array}$ & Yes & Yes & Yes & $\begin{array}{c}\text { No (due to } \\
\text { redundancy) }\end{array}$ & Yes \\
\hline $\begin{array}{l}\text { Type of } \\
\text { Images }\end{array}$ & $\begin{array}{c}\text { Aerial } \\
\text { pictures }\end{array}$ & Gray level & $\begin{array}{c}\text { PAN } \\
\text { (Quickbird } \\
\text { images) }\end{array}$ & $\begin{array}{c}\text { Image and } \\
\text { Vector data }\end{array}$ & $\begin{array}{l}\text { MS and } \\
\text { PAN } \\
\text { (HRSI) }\end{array}$ \\
\hline $\begin{array}{l}\text { Shape } \\
\text { feature }\end{array}$ & Linear & $\begin{array}{c}\text { Rectilinear } \\
\text { or curved } \\
\text { roads }\end{array}$ & $\begin{array}{c}\text { Curvi-linear } \\
\text { features }\end{array}$ & $\begin{array}{l}\text { Elongated } \\
\text { roads }\end{array}$ & $\begin{array}{c}\text { Rectilinear } \\
\text { or curved } \\
\text { roads }\end{array}$ \\
\hline $\begin{array}{c}\text { Automatic } \\
\text { or Semi- } \\
\text { automatic }\end{array}$ & $\begin{array}{c}\text { Semi- } \\
\text { automatic }\end{array}$ & Automatic & Automatic & Automatic & Automatic \\
\hline $\begin{array}{c}\text { Time } \\
\text { complexity }\end{array}$ & Low & Moderate & High & High & Moderate \\
\hline
\end{tabular}

Table 3. Analysis of road detection approaches using different key factors

To analyze the detailed description of road detection results in the various methodologies, a comparative analysis is presented in the Table 3. It shows the detailed description of the utilized information in these approaches. The various hybrid methodologies are presented to analyze the road detection results in the respective of the key properties of these approaches. This kind of comparison helps to consider the 
merits and demerits of the presented approaches. In today's scenario, the moderate level of time complexity is required (Valero et al., 2010; Singh and Garg, 2012). To extract this kind of features, Very HRSI are required and even though HRSI is quite suitable to extract the roads.

\section{PERFORMANCE EVALUATION OF THE HYBRID APPROACHES}

A comparative analysis is presented to analyze the road detection results of the various hybrid methodologies (Table 4). It presents the quantitative performance parameters to show the evaluation the road results. The higher values of completeness and correctness show the better quality of the detecting roads, which are 96.57 and 99.74 (Zelang et al., 2014a) respectively. In addition, these values are also found good (Singh and Garg, 2012; Zelang et al., 2014a), due to the accurate extraction of road results in HRSI. In the similar way, this kind of analysis is also carried out in the developed suburban and urban areas of the HRSI (Table 5). The overall values of quality assessment parameters are found higher (Singh and Garg, 2014b) in comparison to another (Singh and Garg, 2014a) for developed suburban and urban areas.

\begin{tabular}{|c|c|c|c|}
\hline \multirow{2}{*}{$\begin{array}{c}\text { Hybrid approaches for } \\
\text { road detection }\end{array}$} & \multicolumn{3}{|c|}{\begin{tabular}{c} 
Quantitative Performance parameters \\
\cline { 2 - 4 }
\end{tabular}} \\
\hline $\begin{array}{c}\text { Mena and Malpica, } \\
\text { 2005 }\end{array}$ & 81 & $\begin{array}{c}\text { Correctness } \\
\text { (\%) }\end{array}$ & $\begin{array}{c}\text { Accuracy } \\
(\%)\end{array}$ \\
\hline $\begin{array}{c}\text { Singh and Garg, } \\
\text { 2012 }\end{array}$ & 95.32 & 96.52 & 70 \\
\hline $\begin{array}{c}\text { Zarrinpanjeh et al., } \\
\text { 2013 }\end{array}$ & 76.39 & 96.83 & 74.98 \\
\hline Zelang et al., 2014a & 96.57 & 99.74 & 96.33 \\
\hline Zelang et al., 2014b & 95.20 & 96.88 & 92.37 \\
\hline $\begin{array}{c}\text { Zelang and Wenzhong, } \\
\text { 2014 }\end{array}$ & 80.65 & 88.35 & 72.89 \\
\hline
\end{tabular}

Table 4. Performance evaluation of Hybrid approaches for road detection

\begin{tabular}{|c|c|c|c|c|}
\hline \multicolumn{2}{|c|}{$\begin{array}{c}\text { High resolution } \\
\text { satellite images }\end{array}$} & $\begin{array}{c}\text { Quality } \\
\text { assessment } \\
\text { parameters }\end{array}$ & $\begin{array}{c}\text { Singh and } \\
\text { Garg, } \\
\text { 2014a }\end{array}$ & $\begin{array}{c}\text { Singh and } \\
\text { Garg, } \\
\text { 2014b }\end{array}$ \\
\hline \multirow{2}{*}{$\begin{array}{c}\text { Developed } \\
\text { suburban } \\
\text { area }\end{array}$} & $\mathrm{A}_{1}$ & Completeness & 95.85 & 98.85 \\
\cline { 2 - 5 } & $\mathrm{A}_{2}$ & Correctness & 96.24 & 98.94 \\
\cline { 2 - 5 } & Completeness & 95.67 & 98.67 \\
\hline \multirow{2}{*}{$\begin{array}{c}\text { Developed } \\
\text { urban area }\end{array}$} & Completeness & 94.19 & 98.89 \\
\cline { 2 - 5 } & Correctness & 95.20 & 99.78 \\
\hline
\end{tabular}

Table 5. Performance evaluation of the road network extraction in different areas of HRSI

\section{CONCLUSION}

This paper reviews the road characteristics in HRSI that are utilized for detecting the road network. Furthermore, the road results show that the accuracy of classified roads is reduced in some cases, due to the existence of non-road areas in road results. This problem is also addressed with the different approaches in this paper, which are shown with the various kinds of reasons. Therefore, the incorporation of other road information is also required to improve the accuracy of classified road networks. The contribution of hybrid and multistage framework are quite effective to achieve the best level accuracy of road networks, which has been analyzed with the help of quantitative evaluation. On the basis of the key factors in the road detection approaches, various kinds of future scope of work are required to renovate or improve the quality of roads in few cases.

\section{ACKNOWLEDGEMENT}

The work of the first author is supported by MHRD, INDIA. The authors also thank the Geomatics Engg. Lab, Civil Engg. Deptt. and Institute Computer Center, IIT Roorkee for support to carry out the work.

\section{REFERENCES}

Lin, X., Zhang, J., Liu, Z., and Shen, J., 2011. Semi-automatic road tracking by template matching and distance transformation in urban areas. International Journal of Remote Sensing, 32 (23), pp. 8331-8347.

Mena, J. B., and Malpica, J. A., 2005. An automatic method for road extraction in rural and semi-urban areas starting from high resolution satellite imagery. Pattern Recognition Letters, 26(), pp. 1201-1220.

Mohammadzadeh, A., ValadanZoej, M. J., and Tavakoli, A., 2007. Automatic class mean calculation of road surface from Ikonos images using fuzzy logic and particle swarm optimization. In: International Archives of Photogrammetry, Remote Sensing and Spatial Information Sciences, Munich, Germany, Vol. 36 (3/W49B), pp. 119-124.

Mohammadzadeh, A., ValadanZoej, M. J., and Tavakoli, A., 2008. Automatic Main Road Extraction from High Resolution Satellite Imageries by Means of Self-Learning Fuzzy-GA Algorithm. Journal of Applied Sciences, 8(19), pp. 3431-3438.

Mohammadzadeh, A., ValadanZoej, M. J., and Tavakoli, A., 2009. Automatic main road extraction from high resolution satellite imageries by means of particle swarm optimization applied to a fuzzy based mean calculation approach. Journal of the Indian society of remote sensing, 37(2), pp. 173-184.

Poullis, C., and You, S., 2010. Delineation and geometric modeling of road networks. ISPRS Journal of Photogrammetry and Remote Sensing, 65(2), pp.165-181.

Shi, W., Miao, Z., and Debayle, J., 2014. An integrated method for urban main road centerline extraction from optical remotely sensed imagery. IEEE Transactions on Geoscience and Remote Sensing, 52, pp.3359-3372. 
Singh, P. P., and Garg, R. D., 2012. Automatic road extraction from high resolution satellite images using adaptive global thresholding and morphological Operations. Journal of the Indian Society of Remote Sensing, 41(3), pp. 631-640.

Singh, P. P., and Garg, R. D., 2013. Study of Spectral reflectance characteristics of Asphalt Road surface using Geomatics Techniques. In: The International Conference on Advances in Computing, Communications and Informatics, Mysore, India, pp. 516-520.

Singh, P. P., and Garg, R. D., 2014a. Classification of high resolution satellite image using spatial constraints based fuzzy clustering. Journal of Applied Remote Sensing, 8(1), pp. 083526.

Singh, P. P., and Garg, R. D., 2014b. A two-stage framework for road extraction from high-resolution satellite images by using prominent features of impervious surfaces. International Journal of Remote Sensing. DOI: 10.1080/01431161.2014. 978956

Valero, S., Chanussot, J., Benediktsson, J. A., Talbot, H., and Waske, B., 2010. Advanced directional mathematical morphology for the detection of the road network in very high resolution remote sensing images. Pattern Recognition Letters, 31(10), pp. 1120-1127.

Wenzhong, S., Zelang, M., Qunming, W., and Zhang, H., 2014. Spectral-Spatial classification and shape features for urban road centerline extraction. IEEE Geoscience and Remote Sensing Letters, 11, pp. 788-792.

Zarrinpanjeh, N., Samadzadegan, F., and Schenk, T., 2013. A new ant based distributed framework for urban road map updating from high resolution satellite imagery. Computers and Geosciences, 54, pp. 337-350.

Zelang, M., Wenzhong, S., Hua, Z., and Xinxin, W., 2013. Road centerline extraction from high-resolution imagery based on shape features and multivariate adaptive regression splines. IEEE Geoscience and Remote Sensing Letters, 10, pp. 583-587.

Zelang, M., and Wenzhong, S., 2014. Road Centreline extraction from classified images by using the geodesic method. Remote Sensing Letters, 5, pp. 367-376.

Zelang, M., Bin, W., Wenzhong, S., and Hao, W., 2014a. A Method for Accurate Road Centerline Extraction from a Classified Image. IEEE Journal of Selected Topics on Geoscience and Remote Sensing, PP(99), 1.

Zelang, M., Bin, W., Wenzhong, S., and Hua, Z., 2014b. A Semi-Automatic Method for Road Centerline Extraction From VHR Images. IEEE Geoscience and Remote Sensing Letters, 11, pp. 1856-860. 